\title{
Review
}

\section{The Potential Equivalents of TET2 Mutations}

\author{
Sergiu Pasca ${ }^{1,2,3}$, Ancuta Jurj ${ }^{4, *}$, Mihnea Zdrenghea ${ }^{1,3,+}$ (I) and Ciprian Tomuleasa ${ }^{1,2,3,+}$ (i) \\ 1 Department of Hematology, Iuliu Hatieganu University of Medicine and Pharmacy, 400012 Cluj Napoca, \\ Romania; pasca.sergiu123@gmail.com (S.P.); mzdrenghea@umfcluj.ro (M.Z.); \\ ciprian.tomuleasa@umfcluj.ro (C.T.) \\ 2 Medfuture Research Center for Advanced Medicine, Iuliu Hatieganu University of Medicine and Pharmacy, \\ 400349 Cluj Napoca, Romania \\ 3 Department of Hematology, Ion Chiricuta Clinical Cancer Center, 400124 Cluj Napoca, Romania \\ 4 Research Center for Functional Genomics, Biomedicine and Translational Medicine, \\ Iuliu Hatieganu University of Medicine and Pharmacy, 400337 Cluj-Napoca, Romania \\ * Correspondence: anca.jurj@umfcluj.ro \\ + These authors contributed equally to this work and should be considered co-last authors.
}

check for

updates

Citation: Pasca, S.; Jurj, A.;

Zdrenghea, M.; Tomuleasa, C. The Potential Equivalents of TET2

Mutations. Cancers 2021, 13, 1499.

https://doi.org/10.3390/

cancers13071499

Academic Editor: Adriano Venditti

Received: 8 February 2021

Accepted: 22 March 2021

Published: 24 March 2021

Publisher's Note: MDPI stays neutral with regard to jurisdictional claims in published maps and institutional affiliations.

Copyright: (c) 2021 by the authors. Licensee MDPI, Basel, Switzerland. This article is an open access article distributed under the terms and conditions of the Creative Commons Attribution (CC BY) license (https:// creativecommons.org/licenses/by/ $4.0 /)$.
Simple Summary: In acute myeloid leukemia (AML) TET2 mutations have been observed to be mutually exclusive with IDH1, IDH2, and WT1 mutations, all of them showing a similar impact on the transcription profile. Because of this, it is possible that TET2/IDH1/2/WT1 mutated AML could be considered as having similar characteristics between each other. Nonetheless, other genes also interact with TET2 and influence its activity. Because of this, it is possible that other signatures exist that would mimic the effect of TET2 mutations. Thus, in this review, we searched the literature for the genes that were observed to interact with TET2 and classified them in the following manner: transcription alteration, miRs, direct interaction, posttranslational changes, and substrate reduction.

Abstract: TET2 is a dioxygenase dependent on $\mathrm{Fe}^{2+}$ and $\alpha$-ketoglutarate which oxidizes 5-methylcytosine $(5 \mathrm{meC})$ to 5 -hydroxymethylcytosine (5hmeC). TET proteins successively oxidize $5 \mathrm{mC}$ to yield 5 hydroxymethylcytosine ( $5 \mathrm{hmC}), 5$-formylcytosine $(5 \mathrm{fC})$, and 5-carboxylcytosine (5caC). Among these oxidized methylcytosines, $5 \mathrm{fC}$ and $5 \mathrm{caC}$ are directly excised by thymine DNA glycosylase (TDG) and ultimately replaced with unmethylated cytosine. Mutations in TET2 have been shown to lead to a hypermethylated state of the genome and to be responsible for the initiation of the oncogenetic process, especially in myeloid and lymphoid malignancies. Nonetheless, this was also shown to be the case in other cancers. In AML, TET2 mutations have been observed to be mutually exclusive with IDH1, IDH2, and WT1 mutations, all of them showing a similar impact on the transcription profile of the affected cell. Because of this, it is possible that TET2/IDH1/2/WT1 mutated AML could be considered as having similar characteristics between each other. Nonetheless, other genes also interact with TET2 and influence its effect, thus making it possible that other signatures exist that would mimic the effect of TET2 mutations. Thus, in this review, we searched the literature for the genes that were observed to interact with TET2 and classified them in the following manner: transcription alteration, miRs, direct interaction, posttranslational changes, and substrate reduction. What we propose in the present review is the potential extension of the TET2/IDH1/2/WT1 entity with the addition of certain expression signatures that would be able to induce a similar phenotype with that induced by TET2 mutations. Nonetheless, we recommend that this approach be taken on a disease by disease basis.

Keywords: TET2; mutations; equivalent; expression

\section{Introduction}

TET2 is a dioxygenase dependent on $\mathrm{Fe}^{2+}$ and $\alpha$-ketoglutarate which oxidizes 5methylcytosine (5meC) to 5-hydroxymethylcytosine (5hmeC). TET proteins successively 
oxidize $5 \mathrm{mC}$ to yield 5-hydroxymethylcytosine (5hmC), 5-formylcytosine (5fC), and 5carboxylcytosine $(5 \mathrm{caC})$. Among these oxidized methylcytosines, $5 \mathrm{fC}$ and $5 \mathrm{caC}$ are directly excised by thymine DNA glycosylase (TDG) and ultimately replaced with unmethylated cytosine. This mechanism not only provides a pathway for removing the methyl mark from cytosines but also provides a mechanism for generating $5 \mathrm{hmeC}$ marks. The $5 \mathrm{hmeC}$ marks also play an important role in being recognized by certain epigenetic readers leading to further alterations to the expression profile [1]. This mark $(5 \mathrm{hmeC})$ has been observed to be altered in aging, cancer, cell differentiation, and other diseases and biological processes [2]. Added to this, TET2 is also involved in the oxidation of $5 \mathrm{meC}$ to $5 \mathrm{hmeC}$ in RNA species [3].

The function of TET2 was revealed to be of high importance especially regarding myeloid and lymphoid cells. For example, TET2 is essential for the differentiation of monocytes [4]. Added to this, TET2 deletion increases the number of immature myeloid cells (assessed through the c-Kit positive and Lin negative markers) in the bone marrow of murine models. This was one of the arguments that showed the importance of TET2 in myeloid maturation [5]. Moreover, inhibition of the conversion of $5 \mathrm{meC}$ to $5 \mathrm{hmeC}$ induced experimentally through TET2 alteration leads to altered granulopoiesis and erythropoiesis [6]. The effect that TET2 has on erythropoiesis was also observed in a zebrafish model, having a similar role as in mammals [7].

A more direct link between the alteration of this enzyme and the development of certain diseases has been based on the fact that mice lacking TET2 frequently develop myeloid malignancies [8]. More than this, tumor development, in general, is associated with a reduction in 5hmC marks. This is correlated with reduced TET2 activity in lung, prostate, pancreatic, liver, and breast cancers when compared to the surrounding tissue [9]. Added to this, TET2 is also important in the development of angioimmunoblastic T-cell lymphoma (AITL), being one of the first mutations that appear in this disease $[10,11]$. Interestingly, TET2 alterations also induce instability of FOXP3, leading to an important tendency for autoimmunity in murine models $[12,13]$. What has to be mentioned is the fact that AITL is generally associated with autoimmune events, especially autoimmune hemolytic anemia. The association of AITL with autoimmune events is also in accordance with the fact that the cell from which AITL develops is represented by the T-follicular helper cell, which is implicated in stimulating various processes of the immune systems, including antibody production [14]. Even though hematologic malignancies present the most interest regarding TET2 mutations, the literature also contains data regarding the presence of TET2 mutations in other malignancies. Some examples are the field of sarcomas, specifically of chondrosarcoma [15], and glioma where it has been observed to be a driver in the absence of IDH1/2 mutations [16].

Because TET2 is at the center of these mechanisms for epigenetic modifications, the scientific community presented a high interest regarding this enzyme. Nonetheless, the molecules that interact with TET2 are still presenting a high interest in the scientific community as alterations in some of these can mimic the effect of TET2 mutations. Thus, in the present review, we will discuss the genes that influence TET2 activity potentially mimicking the effects of TET2 mutations. This is important as it would represent a step to considering some signatures as having the same effect in a certain malignancy and, thus, considering them as having similar effects to that of TET2 mutations.

\section{Classic Gene Mutations Mimicking TET2 Loss}

Some of the best-studied mutations that influence TET2 activity are represented by mutations in IDH1 and IDH2. In this case, mutations in TET2, IDH1, and IDH2 are mutually exclusive in AML. Normally, both IDH1 (cytoplasmic isoenzyme) and IDH2 (mitochondrial isoenzyme) catalyze the conversion of isocitrate to $\alpha$-ketoglutarate. Mutations in these enzymes generally occur in three hotspots (R132 for IDH1 and R140 and R172 for IDH2) and are all gain-of-function mutations. More specifically, these mutations switch IDH1/2 from converting isocitrate to $\alpha$-ketoglutarate to, instead, to converting $\alpha$-ketoglutarate to 2-hydroxyglutarate. The latter compound (2-hydroxyglutarate) is sterically similar 
to $\alpha$-ketoglutarate and acts as a competitive inhibitor to $\alpha$-ketoglutarate-dependent enzymes [17]. Of those, an important $\alpha$-ketoglutarate dependent enzyme is TET2, with IDH1/2 mutations being able to mimic the effect of TET2 mutations leading to a similar transcriptomic profile as we have previously shown [18].

These mutations are implicated in oncogenesis by impairing cell differentiation and, thus, increasing the number of cancer stem cells in a variety of malignant diseases including AML [19], glioblastoma [20], sarcoma [21], cholangiocarcinoma [22], and others [23]. Interestingly, these mutations appear early in the process of oncogenesis [23]. Because of the role that $I D H 1 / 2$ mutations have in this process, inhibitors have been developed to target these mutations with the best-known ones being represented by ivosidenib and enasidenib. These inhibitors have been used in the treatment of IDH1 and IDH2 mutated AML and have been approved by the Food and Drug Administration [24,25]. Nonetheless, it was proposed that these mutations can also be targeted in other cancers [26]. Added to this, because of the frequency of TET2 and IDH1/2 mutations in lymphomas developed from a T-follicular helper cell (e.g., AITL, peripheral T-cell lymphoma not otherwise specified) drugs targeting epigenetic alterations were also used in clinical trials. In this case, clinical trials have shown the efficacy of azacitidine combined with romidepsin in inducing a response in these diseases. This adds arguments to the fact that these lymphomas are heavily dependent on mutations in epigenetic modifiers $[27,28]$.

The gain-of-function IDH1/2 mutations that convert $\alpha$-ketoglutarate to 2 -hydroxyglutarate, a competitive inhibitor for the TET2 enzyme as well as mutual exclusivity of IDH1 and TET2 mutations in certain cancer types, particularly in AML, lead to the widely accepted concept that mutant IDH1 modulates tumorigenesis through the effect on TET2 activity to alter the tumor epigenetic landscape. However, the lack of complete phenotypic overlap between IDH1 mutant and TET2 mutant cancers suggests that IDH1 can modulate leukemogenesis independently of TET2. For instance, unlike TET2 knock-out mice, mice harboring IDH1 mutations did not show any significant alterations in the proportion of hematopoietic progenitors in the bone marrow, and their bone marrow cells did not show an advantage over wild-type cells in competitive repopulation assays. More importantly, progression to acute leukemia was not reported in IDH1/2 mutant mice [29-31].

Furthermore, while TET2 mutations are more frequent in chronic myelomonocytic leukemia (CMML) than in AML, IDH1/2 mutations are more common in AML than in CMML [32,33]. Unlike TET2 mutations, IDH1/2 mutations are quite rare in clonal hematopoiesis [34,35]. As mentioned before, IDH1/2 and TET2 mutations are not mutually exclusive but rather coexist in a large fraction of patients in some cancers such as AITL. Mutant IDH1 can broadly inhibit the activities of a number of enzymes including approximately $60 \alpha$-ketoglutarate-dependent enzymes and is also shown to downregulate ATM and thus alter DNA repair and sensitivity to DNA damage independent of TET2 [36,37]. Thus, it is also likely that TET2 and IDH1/2 mutations can have at least some differential tumorigenic effects, even if they partly share a common oncogenic mechanism.

Other gene mutations that can be observed to present mutual exclusivity with TET2/IDH1/2 in AML are represented by mutations in WT1. WT1 physically interacts with TET2 and is involved in the action that TET2 has at the DNA level. Mutations at the level of this gene lead to the formation of truncated or nonfunctional forms of WT1 which are either degraded earlier at mRNA level [38] or lack the ability to aid the interaction between TET2 and DNA. Because of this interaction, mutations in WT1 induce a similar effect to that of TET2 mutation [39]. More than this, we have shown that mutations in WT1 are associated with similar methylation and transcriptomic profiles to that of TET2/IDH1/2 mutations in the case of AML [18]. In the same article, we proposed that TET2/IDH1/2/WT1 mutated AML to be considered as being similar to each other. Nonetheless, further data is needed to support this evidence. Conversely, compared to TET2/IDH1/2 mutations, which are generally present as initiating mutations in AML and have a relatively stable presence, WT1 mutations are considered to be secondary events in AML and are much less stable [40]. However, whether WT1 and TET2 mutations share similar transcriptional 
targets or whether they cause similar hematopoietic abnormalities including aberrant hematopoiesis or leukemogenesis has not been directly assessed, particularly in in vivo settings. An overview of the effects of TET2/IDH1/2/WT1 mutations on the function of TET2 is represented in Figure 1.

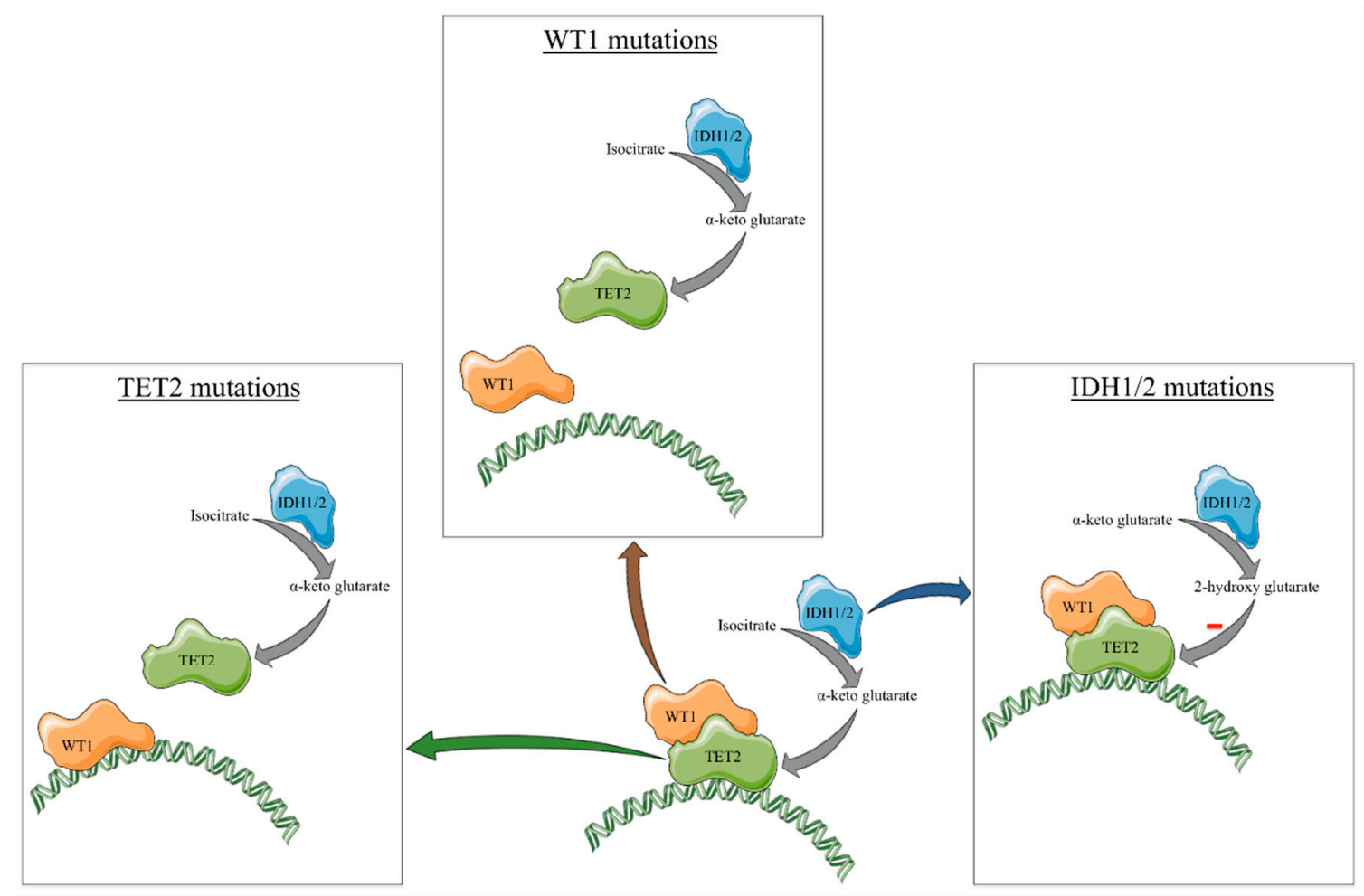

Figure 1. Overview of the mechanisms through which $I D H 1, I D H 2$, and WT1 mutations induce, in some cases, transcriptional profiles similar to those induced by TET2 mutations.

\section{Interactions within the TET2/IDH1/2/WT1 Mutated Cells}

Another important step to be taken is to determine how TET2/IDH1/2/WT1 mutations interact with other mutations or gene expressions to alter the global transcriptomic profile.

In this direction, we studied how TET2/IDH1/2/WT1 mutations affect the mRNA associations of the RUNX1 mRNA. In our study, we observed that TET2/IDH1/2/WT1 mutated AML cases are associated with an increase in negative correlations between the RUNX1 mRNA and other mRNAs. More than this, when assessing the processes in which the negatively correlated genes are involved in we observed the presence of several genes involved in myeloid lineage activity. Because of this, this may be one of the changes that occur in TET2/IDH1/2/WT1 mutated AML that leads to the generation of an immature phenotype of the AML clone [41]. Nonetheless, more studies are needed to better assess the interaction between RUNX1 and TET2.

Another example in this direction is represented by the co-occurrence between DNMT3A and TET2 mutations, which, in theory, should have opposing effects. Interestingly the double knockout of TET2 and DNMT3A showed that the DNA methylation profile has regions that are cooperatively, competitively, and independently influenced by these alterations with KLF1 being an important transcription factor that is upregulated when both TET2 and DNMT3A are deleted [42]. Thus, TET2/IDH1/2/WT1 mutations might induce different methylation and transcriptomic profiles when associated with DNMT3A alterations.

\section{Other Equivalents of TET2 Mutations}

IDH1, IDH2, and WT1 mutations have been thoroughly studied and important evidence has been built to argue for their influence on TET2. Nonetheless, there are still other 
genes that interact with TET2 and have the potential to alter its activity. Not necessarily gene mutations, but alterations in expression or posttranslational modifications in some proteins might heavily influence TET2. Because of this, we consider that it would be possible for additional signatures to exist that offer a phenotype similar to that of TET2 mutations. Further, we will discuss the molecules that interact with TET2. We will refer to these interactions as transcription alteration, miRs, direct interactions, posttranslational changes, and substrate reduction. An overview of the different molecules observed in the literature that we will be further discussing was represented in Figure 2.

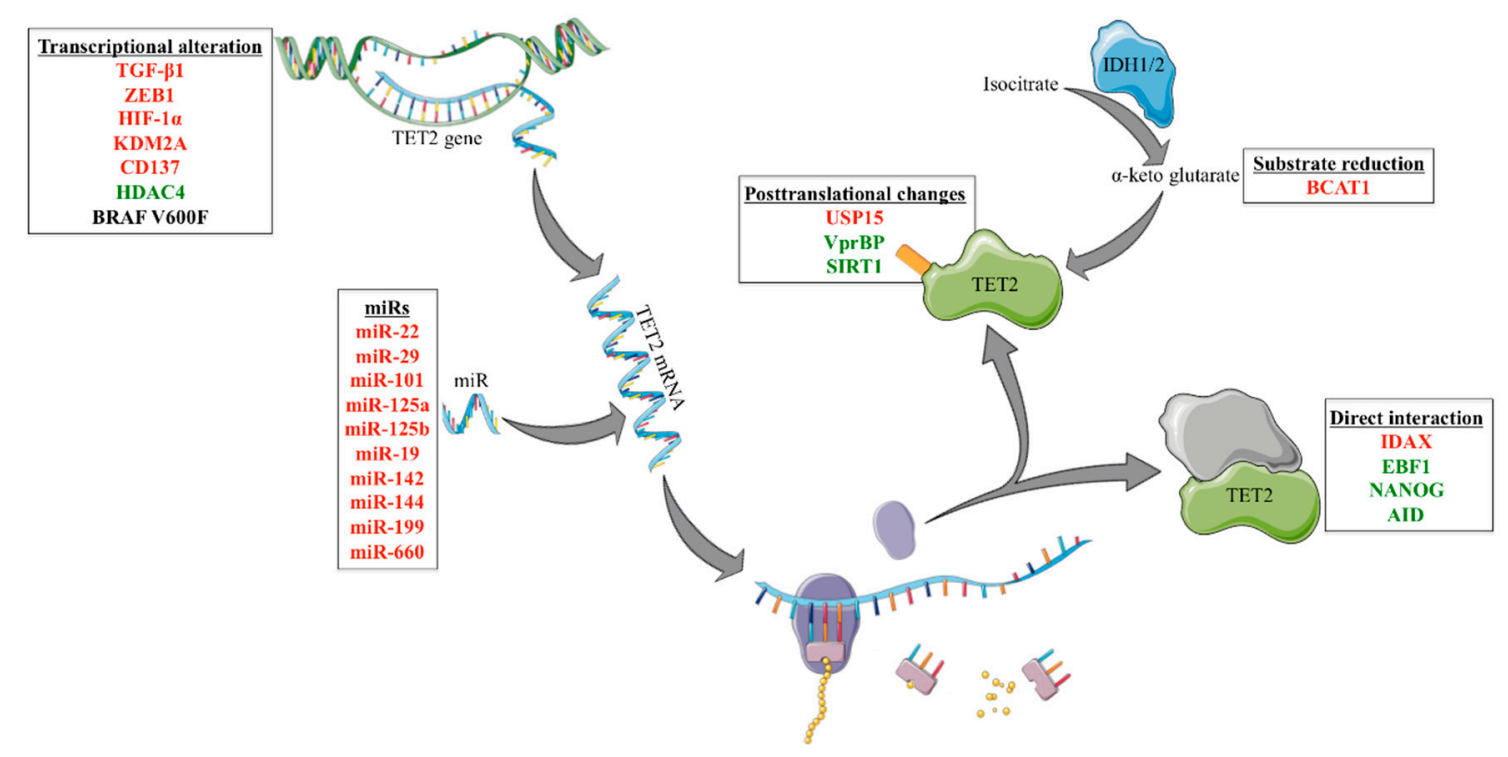

Figure 2. Overview of the genes implicated in the regulation of TET2 activity except for IDH1, IDH2, and WT1 mutations. In the red font, we depicted genes that, when upregulated, would reduce TET2 activity, while, with green, we depicted genes that, when downregulated, would reduce TET2 activity. An exception to this rule is BRAF, in which case we discussed the V600F mutation and not an expression alteration. Additionally, in the case of direct interaction, we also depicted synergy as green.

\subsection{Transcription Alteration}

In melanoma, TGF- $\beta 1$ determines the recruitment of DNMT3A to the TET2 gene locus, methylation of this gene, and subsequent silencing of TET2 expression, which induces an increase in the process of epithelial-mesenchymal transition [43]. Because this process is dependent on DNMT3A, an interesting research direction would be to delete DNMT3A and determine if this phenomenon is still present. Conversely, in diabetic nephropathy, TET2 acts as a regulator of TGF- $\beta 1$ by initiating the process of demethylation at the TGF- $\beta 1$ regulatory regions and increasing its expression [44]. Because of this, it is possible that TGF- $\beta 1$ acts as an indirect negative regulator for its own expression. Nonetheless, this hypothesis has to be validated in the same disease (e.g., AML) for it to reveal a reliable signaling pathway.

In glioma, ZEB1 binds to the TET2 promoter repressing its expression. The reduction in TET2 expression is associated with an increase in glioma invasion and growth [45].

In melanoma cells, HIF-1 $\alpha$ downregulation increases TET2 expression both considering the mRNA and protein levels [46].

In breast cancer KDM2A interacts with RelA and acts on the promoter of TET2, inhibiting TET2 expression. This is in accordance with the fact that $K D M 2 A$ knock-down is associated with TET2 overexpression, while $K D M 2 A$ ectopic expression suppresses TET2 transcription. More than this, KDM2A knock-down is associated with an increase in genomic 5hmeC marks [47]. 
CD137 activation decreases the expression of TET2 in endothelial cells. More than this, CD137 activation also inhibits the transfer of exosomes loaded with TET2 from endothelial cells to vascular smooth muscle cells. Because of this, CD137 decreases the anti-inflammatory protection offered by TET2 and increases the process of neointimal formation. It has to be mentioned that this study did not assess promoter binding of any molecules activated by CD137 but only the expression patterns [48].

In myelodysplastic syndrome (MDS) and AML cells, HDAC4 inhibition leads to the downregulation of TET2 and the subsequent decrease in the abundance of 5hmeC marks [49].

In colon cancer, BRAF V600F was associated with the downregulation of TET2 and subsequent DNA hypermethylation [50].

\section{2. $\mathrm{miRs}$}

miRs have also been observed to target TET2 mRNA, thus influencing the abundance of TET2 that can perform its function. Using the miRTargetLink Human software [51], we observed that there were 8 miRs presenting strong evidence, 9 presenting weak evidence, and 89 predicted of interacting with TET2. The miRs presenting strong evidence were represented by: miR-22-3p, miR-101-3p, miR-29a-3p, miR-29b-3p, miR-29c-3p, miR-26a-5p, miR-7-5p and miR-125b-5p. The miRs presenting weak evidence were represented by: miR-335-5p, miR-484, miR-92a-3p, miR-5011-5p, miR-1277-5p, miR-3924, miR-190-3p, miR4775 and $\mathrm{miR}-590-3 \mathrm{p}$. We further chose to assess the miRs presenting strong evidence by introducing them in miRNET [52] using bone marrow as the selected tissue and miRTarBase v8.0 [53] as the database for miR targets. Using this algorithm, the network generated contained 2117 genes and 2804 edges. Aside from TET2, which was targeted by all of the assessed miRs, we also find it important to mention that DNMT3A was targeted by 4 of these miRs, showing that TET2 and DNMT3A do not necessarily have to act in antagonism. Interestingly, we also found SIRT1 to be targeted by 2 of these miRs. This is important as SIRT1 deacetylates the c-terminus portion of TET2 and increases its activity [54]. We also assessed the KEGG pathways that are enriched considering these genes and we would like to mention the following KEGG [55] terms preceded by the number of genes associated with that term: 24 genes for AML, 35 for glioma, 27 genes for apoptosis, 28 genes for the p53 signaling, 21 genes for the mTOR signaling pathway, 44 genes for the WNT signaling pathway and 29 genes for the TGF- $\beta$ signaling pathway.

MiR-22 was shown to be upregulated in MDS and to be associated with a reduction in the global abundance of the 5 hmeC mark. This was caused by the fact that miR-22 targets TET2 and reduces its abundance. Transgenic mice overexpressing miR-22 in the hematopoietic compartment present hematopoietic stem cells that have an increased ability to undergo self-renewal, but a reduced ability to differentiate, thus setting the basis for leukemic transformation [56]. Added to this, miR-22-3p is also implicated in the process of vascular smooth muscle cell differentiation by impairing TET2 translation. More than this, the circular RNA circMAP3K5 can sponge miR-22-3p, increasing the effects of TET2, which mediates vascular smooth muscle cell differentiation [57].

MiR-29 targets TET2 and increases the WNT/ $\beta$-catenin leading to reduced efficiency in the reprogramming of fibroblasts to stem cells. An additional argument of this effect is that, naturally, in the process of reprogramming, miR-29 is downregulated [58]. In the case of porcine early embryo development, miR-29b was observed to influence DNA methylation by targeting TET1/2/3 and DNMT3A/B, thus potentially having an effect both on demethylation as well as on de novo methylation [59].

In human umbilical vein endothelial cells, the upregulation of miR-101-3p is associated with increased production of reactive oxygen species and the upregulation of NFk $\beta$. These effects are mediated through the repression of TET2 translation by miR-101-3p, which thus reduces TET2 anti-inflammatory activity [60].

In an MLL-AF9 AML murine model, miR-125b targets TET2 leading to the upregulation of VEGF-A and subsequent increase in AML cell proliferation and apoptosis 
reduction [61]. In giant cell bone tumors, miR-125a upregulation is associated with tumor growth and recurrence. This effect is caused by the inhibition of TET2, which increases the IL-17A expression [62]. MiR-125a-5p is also implicated in the pyroptosis of endothelial cells when stimulated by oxidized low-density lipoproteins. This process was determined to be caused by the miR-125a-5p mediated inhibition of TET2 that determined alterations at several levels including DNA methylation, mitochondrial processes, and the production of reactive oxygen species. These effects were further associated with overexpression of $I L-1 \beta$ and $I L-18$, cytokines implicated in the inflammatory process [63].

We have to mention that we found miRs in the literature that did not appear in the searched database which we will be further discussing.

MiR-19a-5p targets TET2 in glioblastoma inducing proliferation and metastasis. Interestingly, miR-19a-5p was shown to be sponged by the lncRNA AC016405.3 which repressed the glioblastoma cells by reestablishing the expression of TET2 [64].

In Treg cells from models of type 1 diabetes, miR-142-3p targets TET2, thus affecting the activity of FOXP3 and leading to the reduction of the activity of Treg cells [12].

In bone marrow stem cells from patients with aplastic anemia, miR-144-3p inhibits osteogenic differentiation by targeting TET2 [65].

In osteoblasts from ovariectomized mice, miR-199a-5p was decreased compared to the controls. This observation was associated with TET2 upregulation and a decrease in osteoblast differentiation. Conversely, miR-199a-5p upregulation and subsequent TET2 downregulation were associated with better bone development and upregulation of genes involved in the osteogenesis process [66].

In breast cancer cells, miR-660-5p targets TET2 and is associated with a higher stage and an increased vascular invasion in breast cancer patients. In in vitro assays, these results were confirmed by showing that miR-660-5p downregulation was associated with a reduced invasion and an increased apoptosis rate. More than this, aside from the downregulation of TET2, these effects are also mediated through the increased activity of the PI3K/AKT/mTOR signaling pathway [67].

\subsection{Direct Interaction}

IDAX was originally encoded within an ancestral TET2 gene that underwent a chromosomal gene inversion during evolution, thus separating the TET2 CXXC domain from the catalytic domain. Moreover, it has been shown that IDAX interacts with the catalytic domain of TET2. It also has to be mentioned that IDAX upregulation is associated with TET2 downregulation and caspase activation. Because of this, it is thought that IDAX can interact with DNA localized TET2 and induce the degradation of TET2 [68]. Because of this, the IDAX expression level after a certain cutoff might be equivalent to TET2 mutations.

EBF1 interacts with TET2 in multiple cancers like glioma, AML, and chondrosarcoma. Added to this, EBF1 co-localizes with TET2 in hypermethylated loci of the DNA [69]. EBF1 also induces specific chromatin modifications in B-cell development. These changes occur in processes like VDJ rearrangement and antigen stimulation [70]. Conversely, EBF1 is localized in hypomethylated regions in the case of breast cancer [71]. Because of this, EBF1 might influence the effect that TET2 has on the DNA, with alterations in EBF1 also having a potential impact on the activity of TET2.

NANOG can physically interact with TET2 with an important role in the mechanisms of pluripotency of stem cells. It has been observed that the knockout of TET2 diminishes the effect of NANOG because of the direct interaction it has with TET2 in normal circumstances. More than this, co-expression of NANOG and TET2 increases stem cell pluripotency. A further argument to the interaction between TET2 and NANOG is represented by the fact that they co-localize at various genomic loci [72].

In diffuse large $B$ cell lymphoma, activation-induced cytidine deaminase (AID) cooperates with TET2 binding to the FANCA promoter and thus increasing the expression of $F A N C A$. Because of these results, the authors of the study proposed the combined use of 
AID and TET2 depletion in addition to bortezomib to better manage diffuse large B cell lymphoma [73].

\subsection{Posttranslational Changes}

An important part of protein regulation is represented by ubiquitylation which classically has been described as a way for protein degradation. Nonetheless, it has been shown that ubiquitylation can regulate different pathways, being involved as a posttranslational modification that influences signal transmission [74]. In the case of TET2, two proteins have been studied in conjunction with TET2, namely VprBP and USP15. VprBP is implicated in the last step of ubiquitylation leading to the transfer of ubiquitin from E2 to the substrate. This is important in our case because it has been shown that this enzyme monoubiquitylates TET2 at the position K1299 promoting its binding to chromatin. More than this, it has been observed that the lack of this signal leads to a reduction in the activity of TET2 with a subsequent reduction of $5 \mathrm{hmC}$ marks in the genome. $\mathrm{VprBP}$ has been shown to bind to the cysteine-rich domain of TET2, even if TET2 is present in a truncated form, lacking its active site. This shows that VprBP binding is independent to TET2 and the catalytic activity of TET2 [75]. Conversely, USP15 deubiquitylates TET2 K1299, negatively regulating TET2 activity. The deletion of USP15 in melanoma cells increases TET2 activity. This activates the IFN/JAK/STAT signaling pathway in the T-cells from the tumor microenvironment through the increase in the IFN $\gamma$ secretion [76].

SIRT1 was observed to inhibit MDS maintenance in a TET2 dependent manner by deacetylating the c-terminus end of TET2. This change determines the normal maintenance of hematopoietic stem cells in stress conditions. Conversely, SIRT1 downregulation was observed in the case of MDS. The authors of the study also proposed the use of SIRT1 activation as a therapeutic approach in MDS as it would enhance the ability of stem cells to resist in the context of a pro-inflammatory microenvironment [54].

\subsection{Substrate Reduction}

One manner through which other molecular traits could lead to a similar phenotype to that of TET2/IDH1/2/WT1 mutant cells is through the reduction of the substrates of TET2. In this direction, BCAT1 upregulation in AML cells determines a reduction in $\alpha$-ketoglutarate, which mimics the effect of IDH1/2 mutations [77].

\section{Concluding Remarks and Future Perspectives}

Thus, the knowledge about the molecular species that influence TET2 activity has greatly increased from that of $I D H 1, I D H 2$, and WT1 mutations to several factors influencing TET2 expression, translation, posttranslational marks, substrate, and the direct effect that TET2 has. Nonetheless, it has to be mentioned that IDH1, IDH2, and WT1 were assessed as gene mutations whereas most of the other molecular species mentioned here take into consideration their expression level. This is important as gene mutations are more reliably detected compared to expression levels which could be influenced by study errors. More than this, in this review we presented the interactions that TET2 has across different malignancies, cardiovascular diseases, and other conditions. Considering that there might be a difference between the effect that TET2 and IDH1/2 mutations have between AML and AITL, the present review has to be taken with a certain caution and be used to orient at some genes and then validate them on the disease of interest as having a similar effect to that of TET2 mutations.

From a clinical standpoint, mutations are easier to be assessed in the clinical scenario, several hematology clinics having mutational panels available that are tailored to each disease subset, whereas expression of different genes is rarely if ever, assessed in the current clinical practice, implementing the proposed equivalents difficult at this point in time. Nonetheless, with the advancement of clinical assessments, there might be a point at which routine gene expression could be done in the clinical scenario. 
What we propose in the present review is the potential extension of the TET2/IDH1/2/WT1 entity with additional expression signatures that would be able to induce a similar phenotype to the cell of interest. Nonetheless, we recommend that this approach be taken on a disease by disease basis.

Author Contributions: S.P. and A.J. contrbuted to the initial manuscript writing. M.Z. and C.T. contributed to the final editing of the manuscript and supervising. C.T. contributed to the funding acquisition. All authors have read and agreed to the published version of the manuscript.

Funding: This work was supported by a grant from the Romanian Ministry of Research and Innovation, CCCDI-UEFISCDI, Project No. PN-III-P4-ID-PCCF-2016-0112 within PNCDI III, as well as by awarded for Young Research Teams 2020-2022 (Grant No. PN-III-P1-1.1-TE-2019-0271) and by an international collaborative grant of the European Economic Space between Romania and Iceland 2020-2022 (Grant No. 19-COP-0031). Added to this, Sergiu Pasca was supported by an internal grant of the "Iuliu Haţieganu" University of Medicine and Pharmacy (UMPh), Cluj-Napoca, for sustaining Ph.D. Research Project.

Conflicts of Interest: The authors declare no conflict of interest.

\section{References}

1. Feng, Y.; Li, X.; Cassady, K.; Zou, Z.; Zhang, X. TET2 Function in Hematopoietic Malignancies, Immune Regulation, and DNA Repair. Front. Oncol. 2019, 9, 210. [CrossRef] [PubMed]

2. López, V.; Fernández, A.F.; Fraga, M.F. The Role of 5-Hydroxymethylcytosine in Development, Aging and Age-Related Diseases. Ageing Res. Rev. 2017, 37, 28-38. [CrossRef]

3. Xu, Q.; Wang, K.; Wang, L.; Zhu, Y.; Zhou, G.; Xie, D.; Yang, Q. IDH1/2 Mutants Inhibit TET-Promoted Oxidation of RNA 5mC to 5hmC. PLoS ONE 2016, 11, e0161261. [CrossRef]

4. Solary, E.; Bernard, O.A.; Tefferi, A.; Fuks, F.; Vainchenker, W. The Ten-Eleven Translocation-2 (TET2) Gene in Hematopoiesis and Hematopoietic Diseases. Leukemia 2014, 28, 485-496. [CrossRef]

5. Moran-Crusio, K.; Reavie, L.; Shih, A.; Abdel-Wahab, O.; Ndiaye-Lobry, D.; Lobry, C.; Figueroa, M.E.; Vasanthakumar, A.; Patel, J.; Zhao, X.; et al. Tet2 Loss Leads to Increased Hematopoietic Stem Cell Self-Renewal and Myeloid Transformation. Cancer Cell 2011, 20, 11-24. [CrossRef]

6. Pronier, E.; Almire, C.; Mokrani, H.; Vasanthakumar, A.; Simon, A.; da Costa Reis Monte Mor, B.; Massé, A.; Le Couédic, J.-P.; Pendino, F.; Carbonne, B.; et al. Inhibition of TET2-Mediated Conversion of 5-Methylcytosine to 5-Hydroxymethylcytosine Disturbs Erythroid and Granulomonocytic Differentiation of Human Hematopoietic Progenitors. Blood 2011, 118, $2551-2555$. [CrossRef]

7. Ge, L.; Zhang, R.-P.; Wan, F.; Guo, D.-Y.; Wang, P.; Xiang, L.-X.; Shao, J.-Z. TET2 Plays an Essential Role in Erythropoiesis by Regulating Lineage-Specific Genes via DNA Oxidative Demethylation in a Zebrafish Model. Mol. Cell. Biol. 2014, 34, $989-1002$. [CrossRef]

8. Li, Z.; Cai, X.; Cai, C.-L.; Wang, J.; Zhang, W.; Petersen, B.E.; Yang, F.-C.; Xu, M. Deletion of Tet2 in Mice Leads to Dysregulated Hematopoietic Stem Cells and Subsequent Development of Myeloid Malignancies. Blood 2011, 118, 4509-4518. [CrossRef]

9. Yang, H.; Liu, Y.; Bai, F.; Zhang, J.-Y.; Ma, S.-H.; Liu, J.; Xu, Z.-D.; Zhu, H.-G.; Ling, Z.-Q.; Ye, D.; et al. Tumor Development Is Associated with Decrease of TET Gene Expression and 5-Methylcytosine Hydroxylation. Oncogene 2013, 32, 663-669. [CrossRef]

10. Odejide, O.; Weigert, O.; Lane, A.A.; Toscano, D.; Lunning, M.A.; Kopp, N.; Kim, S.; van Bodegom, D.; Bolla, S.; Schatz, J.H.; et al. A Targeted Mutational Landscape of Angioimmunoblastic T-Cell Lymphoma. Blood 2014, 123, 1293-1296. [CrossRef]

11. Yao, W.-Q.; Wu, F.; Zhang, W.; Chuang, S.-S.; Thompson, J.S.; Chen, Z.; Zhang, S.-W.; Clipson, A.; Wang, M.; Liu, H.; et al. Angioimmunoblastic T-Cell Lymphoma Contains Multiple Clonal T-Cell Populations Derived from a Common TET2 Mutant Progenitor Cell. J. Pathol. 2020, 250, 346-357. [CrossRef]

12. Scherm, M.G.; Serr, I.; Zahm, A.M.; Schug, J.; Bellusci, S.; Manfredini, R.; Salb, V.K.; Gerlach, K.; Weigmann, B.; Ziegler, A.-G.; et al. MiRNA142-3p Targets Tet2 and Impairs Treg Differentiation and Stability in Models of Type 1 Diabetes. Nat. Commun. 2019, 10, 5697. [CrossRef]

13. Yue, X.; Lio, C.-W.J.; Samaniego-Castruita, D.; Li, X.; Rao, A. Loss of TET2 and TET3 in Regulatory T Cells Unleashes Effector Function. Nat. Commun. 2019, 10, 2011. [CrossRef]

14. Cortés, J.R.; Palomero, T. The Curious Origins of Angioimmunoblastic T-Cell Lymphoma. Curr. Opin. Hematol. 2016, 23, 434-443. [CrossRef] [PubMed]

15. Venneker, S.; Szuhai, K.; Hogendoorn, P.C.W.; Bovée, J.V.M.G. Mutation-Driven Epigenetic Alterations as a Defining Hallmark of Central Cartilaginous Tumours, Giant Cell Tumour of Bone and Chondroblastoma. Virchows Arch. 2020, 476, 135-146. [CrossRef]

16. Kim, Y.-H.; Pierscianek, D.; Mittelbronn, M.; Vital, A.; Mariani, L.; Hasselblatt, M.; Ohgaki, H. TET2 Promoter Methylation in Low-Grade Diffuse Gliomas Lacking IDH1/2 Mutations: Figure 1. J. Clin. Pathol. 2011, 64, 850-852. [CrossRef]

17. Xu, W.; Yang, H.; Liu, Y.; Yang, Y.; Wang, P.; Kim, S.-H.; Ito, S.; Yang, C.; Wang, P.; Xiao, M.-T.; et al. Oncometabolite 2Hydroxyglutarate Is a Competitive Inhibitor of $\alpha$-Ketoglutarate-Dependent Dioxygenases. Cancer Cell 2011, 19, 17-30. [CrossRef] 
18. Pasca, S.; Turcas, C.; Jurj, A.; Teodorescu, P.; Iluta, S.; Hotea, I.; Bojan, A.; Selicean, C.; Fetica, B.; Petrushev, B.; et al. The Influence of Methylating Mutations on Acute Myeloid Leukemia: Preliminary Analysis on 56 Patients. Diagnostics 2020, 10, 263. [CrossRef]

19. Chen, C.; Liu, Y.; Lu, C.; Cross, J.R.; Morris, J.P.; Shroff, A.S.; Ward, P.S.; Bradner, J.E.; Thompson, C.; Lowe, S.W. Cancer-Associated IDH2 Mutants Drive an Acute Myeloid Leukemia That Is Susceptible to Brd4 Inhibition. Genes Dev. 2013, 27, 1974-1985. [CrossRef]

20. Bardella, C.; Al-Dalahmah, O.; Krell, D.; Brazauskas, P.; Al-Qahtani, K.; Tomkova, M.; Adam, J.; Serres, S.; Lockstone, H.; Freeman-Mills, L.; et al. Expression of Idh1R132H in the Murine Subventricular Zone Stem Cell Niche Recapitulates Features of Early Gliomagenesis. Cancer Cell 2016, 30, 578-594. [CrossRef]

21. Lu, C.; Venneti, S.; Akalin, A.; Fang, F.; Ward, P.S.; DeMatteo, R.G.; Intlekofer, A.M.; Chen, C.; Ye, J.; Hameed, M.; et al. Induction of Sarcomas by Mutant IDH2. Genes Dev. 2013, 27, 1986-1998. [CrossRef]

22. Saha, S.K.; Parachoniak, C.A.; Ghanta, K.S.; Fitamant, J.; Ross, K.N.; Najem, M.S.; Gurumurthy, S.; Akbay, E.A.; Sia, D.; Cornella, H.; et al. Mutant IDH Inhibits HNF-4 $\alpha$ to Block Hepatocyte Differentiation and Promote Biliary Cancer. Nature 2014, 513, 110-114. [CrossRef]

23. Gagné, L.M.; Boulay, K.; Topisirovic, I.; Huot, M.-É.; Mallette, F.A. Oncogenic Activities of IDH1/2 Mutations: From Epigenetics to Cellular Signaling. Trends Cell Biol. 2017, 27, 738-752. [CrossRef] [PubMed]

24. Roboz, G.J.; DiNardo, C.D.; Stein, E.M.; de Botton, S.; Mims, A.S.; Prince, G.T.; Altman, J.K.; Arellano, M.L.; Donnellan, W.; Erba, H.P.; et al. Ivosidenib Induces Deep Durable Remissions in Patients with Newly Diagnosed IDH1-Mutant Acute Myeloid Leukemia. Blood 2020, 135, 463-471. [CrossRef] [PubMed]

25. Stein, E.M.; DiNardo, C.D.; Pollyea, D.A.; Fathi, A.T.; Roboz, G.J.; Altman, J.K.; Stone, R.M.; DeAngelo, D.J.; Levine, R.L.; Flinn, I.W.; et al. Enasidenib in Mutant IDH2 Relapsed or Refractory Acute Myeloid Leukemia. Blood 2017, 130, 722-731. [CrossRef] [PubMed]

26. Golub, D.; Iyengar, N.; Dogra, S.; Wong, T.; Bready, D.; Tang, K.; Modrek, A.S.; Placantonakis, D.G. Mutant Isocitrate Dehydrogenase Inhibitors as Targeted Cancer Therapeutics. Front. Oncol. 2019, 9, 417. [CrossRef]

27. O'Connor, O.A.; Falchi, L.; Lue, J.K.; Marchi, E.; Kinahan, C.; Sawas, A.; Deng, C.; Montanari, F.; Amengual, J.E.; Kim, H.A.; et al. Oral 5-Azacytidine and Romidepsin Exhibit Marked Activity in Patients with PTCL: A Multicenter Phase 1 Study. Blood 2019, 134, 1395-1405. [CrossRef] [PubMed]

28. Lemonnier, F.; Dupuis, J.; Sujobert, P.; Tournillhac, O.; Cheminant, M.; Sarkozy, C.; Pelletier, L.; Marçais, A.; Robe, C.; Fataccioli, V.; et al. Treatment with 5-Azacytidine Induces a Sustained Response in Patients with Angioimmunoblastic T-Cell Lymphoma. Blood 2018, 132, 2305-2309. [CrossRef]

29. Rasmussen, K.D.; Jia, G.; Johansen, J.V.; Pedersen, M.T.; Rapin, N.; Bagger, F.O.; Porse, B.T.; Bernard, O.A.; Christensen, J.; Helin, K. Loss of TET2 in Hematopoietic Cells Leads to DNA Hypermethylation of Active Enhancers and Induction of Leukemogenesis. Genes Dev. 2015, 29, 910-922. [CrossRef]

30. Sasaki, M.; Knobbe, C.B.; Munger, J.C.; Lind, E.F.; Brenner, D.; Brüstle, A.; Harris, I.S.; Holmes, R.; Wakeham, A.; Haight, J.; et al. IDH1(R132H) Mutation Increases Murine Haematopoietic Progenitors and Alters Epigenetics. Nature 2012, 488, 656-659. [CrossRef] [PubMed]

31. Joberty, G.; Boesche, M.; Brown, J.A.; Eberhard, D.; Garton, N.S.; Humphreys, P.G.; Mathieson, T.; Muelbaier, M.; Ramsden, N.G.; Reader, V.; et al. Interrogating the Druggability of the 2-Oxoglutarate-Dependent Dioxygenase Target Class by Chemical Proteomics. ACS Chem. Biol. 2016, 11, 2002-2010. [CrossRef]

32. Jankowska, A.M.; Makishima, H.; Tiu, R.V.; Szpurka, H.; Huang, Y.; Traina, F.; Visconte, V.; Sugimoto, Y.; Prince, C.; O’Keefe, C.; et al. Mutational Spectrum Analysis of Chronic Myelomonocytic Leukemia Includes Genes Associated with Epigenetic Regulation: UTX, EZH2, and DNMT3A. Blood 2011, 118, 3932-3941. [CrossRef] [PubMed]

33. Inoue, S.; Lemonnier, F.; Mak, T.W. Roles of IDH1/2 and TET2 Mutations in Myeloid Disorders. Int. J. Hematol. 2016, 103, 627-633. [CrossRef]

34. Busque, L.; Patel, J.P.; Figueroa, M.E.; Vasanthakumar, A.; Provost, S.; Hamilou, Z.; Mollica, L.; Li, J.; Viale, A.; Heguy, A.; et al. Recurrent Somatic TET2 Mutations in Normal Elderly Individuals with Clonal Hematopoiesis. Nat. Genet. 2012, 44, $1179-1181$. [CrossRef]

35. Zheng, G.; Chen, P.; Pallavajjalla, A.; Haley, L.; Gondek, L.; Dezern, A.; Ling, H.; De Marchi, F.; Lin, M.; Gocke, C. The Diagnostic Utility of Targeted Gene Panel Sequencing in Discriminating Etiologies of Cytopenia. Am. J. Hematol. 2019, 94, 1141-1148. [CrossRef] [PubMed]

36. Horbinski, C. What Do We Know about IDH1/2 Mutations so Far, and How Do We Use It? Acta Neuropathol. 2013, 125, 621-636. [CrossRef] [PubMed]

37. Inoue, S.; Li, W.Y.; Tseng, A.; Beerman, I.; Elia, A.J.; Bendall, S.C.; Lemonnier, F.; Kron, K.J.; Cescon, D.W.; Hao, Z.; et al. Mutant IDH1 Downregulates ATM and Alters DNA Repair and Sensitivity to DNA Damage Independent of TET2. Cancer Cell 2016, 30 , 337-348. [CrossRef]

38. Abbas, S.; Erpelinck-Verschueren, C.A.J.; Goudswaard, C.S.; Löwenberg, B.; Valk, P.J.M. Mutant Wilms' Tumor 1 (WT1) MRNA with Premature Termination Codons in Acute Myeloid Leukemia (AML) Is Sensitive to Nonsense-Mediated RNA Decay (NMD). Leukemia 2010, 24, 660-663. [CrossRef] [PubMed]

39. Wang, Y.; Xiao, M.; Chen, X.; Chen, L.; Xu, Y.; Lv, L.; Wang, P.; Yang, H.; Ma, S.; Lin, H.; et al. WT1 Recruits TET2 to Regulate Its Target Gene Expression and Suppress Leukemia Cell Proliferation. Mol. Cell 2015, 57, 662-673. [CrossRef] [PubMed] 
40. Krauth, M.-T.; Alpermann, T.; Bacher, U.; Eder, C.; Dicker, F.; Ulke, M.; Kuznia, S.; Nadarajah, N.; Kern, W.; Haferlach, C.; et al. WT1 Mutations Are Secondary Events in AML, Show Varying Frequencies and Impact on Prognosis between Genetic Subgroups. Leukemia 2015, 29, 660-667. [CrossRef] [PubMed]

41. Pasca, S.; Jurj, A.; Tomuleasa, C.; Zdrenghea, M. TET2/IDH1/2/WT1 and NPM1 Mutations Influence the RUNX1 Expression Correlations in Acute Myeloid Leukemia. Medicina 2020, 56, 637. [CrossRef] [PubMed]

42. Zhang, X.; Su, J.; Jeong, M.; Ko, M.; Huang, Y.; Park, H.J.; Guzman, A.; Lei, Y.; Huang, Y.-H.; Rao, A.; et al. DNMT3A and TET2 Compete and Cooperate to Repress Lineage-Specific Transcription Factors in Hematopoietic Stem Cells. Nat. Genet. 2016, 48, 1014-1023. [CrossRef]

43. Gong, F.; Guo, Y.; Niu, Y.; Jin, J.; Zhang, X.; Shi, X.; Zhang, L.; Li, R.; Chen, L.; Ma, R.Z. Epigenetic Silencing of TET2 and TET3 Induces an EMT-like Process in Melanoma. Oncotarget 2017, 8, 315-328. [CrossRef]

44. Yang, L.; Zhang, Q.; Wu, Q.; Wei, Y.; Yu, J.; Mu, J.; Zhang, J.; Zeng, W.; Feng, B. Effect of TET2 on the Pathogenesis of Diabetic Nephropathy through Activation of Transforming Growth Factor B1 Expression via DNA Demethylation. Life Sci. 2018, 207, 127-137. [CrossRef]

45. Chen, B.; Lei, Y.; Wang, H.; Dang, Y.; Fang, P.; Wang, J.; Yang, J.; Liu, L. Repression of the Expression of TET2 by ZEB1 Contributes to Invasion and Growth in Glioma Cells. Mol. Med. Rep. 2017, 15, 2625-2632. [CrossRef] [PubMed]

46. Fischer, A.P.; Miles, S.L. Silencing HIF-1 $\alpha$ Induces TET2 Expression and Augments Ascorbic Acid Induced 5-Hydroxymethylation of DNA in Human Metastatic Melanoma Cells. Biochem. Biophys. Res. Commun. 2017, 490, 176-181. [CrossRef] [PubMed]

47. Chen, J.-Y.; Luo, C.-W.; Lai, Y.-S.; Wu, C.-C.; Hung, W.-C. Lysine Demethylase KDM2A Inhibits TET2 to Promote DNA Methylation and Silencing of Tumor Suppressor Genes in Breast Cancer. Oncogenesis 2017, 6, e369. [CrossRef]

48. Li, B.; Zang, G.; Zhong, W.; Chen, R.; Zhang, Y.; Yang, P.; Yan, J. Activation of CD137 Signaling Promotes Neointimal Formation by Attenuating TET2 and Transferrring from Endothelial Cell-Derived Exosomes to Vascular Smooth Muscle Cells. Biomed. Pharmacother. 2020, 121, 109593. [CrossRef]

49. Huang, F.; Sun, J.; Chen, W.; He, X.; Zhu, Y.; Dong, H.; Wang, H.; Li, Z.; Zhang, L.; Khaled, S.; et al. HDAC4 Inhibition Disrupts TET2 Function in High-Risk MDS and AML. Aging (Albany NY) 2020, 12, 16759-16774. [CrossRef]

50. Noreen, F.; Küng, T.; Tornillo, L.; Parker, H.; Silva, M.; Weis, S.; Marra, G.; Rad, R.; Truninger, K.; Schär, P. DNA Methylation Instability by BRAF-Mediated TET Silencing and Lifestyle-Exposure Divides Colon Cancer Pathways. Clin. Epigenet. 2019, 11, 196. [CrossRef]

51. Hamberg, M.; Backes, C.; Fehlmann, T.; Hart, M.; Meder, B.; Meese, E.; Keller, A. MiRTargetLink-MiRNAs, Genes and Interaction Networks. Int. J. Mol. Sci. 2016, 17, 564. [CrossRef]

52. Fan, Y.; Xia, J. miRNet-Functional Analysis and Visual Exploration of miRNA-Target Interactions in a Network Context. In Computational Cell Biology; Methods in Molecular Biology; von Stechow, L., Santos Delgado, A., Eds.; Springer: New York, NY, USA, 2018; Volume 1819, pp. 215-233. ISBN 978-1-4939-8617-0.

53. Huang, H.-Y.; Lin, Y.-C.-D.; Li, J.; Huang, K.-Y.; Shrestha, S.; Hong, H.-C.; Tang, Y.; Chen, Y.-G.; Jin, C.-N.; Yu, Y.; et al. MiRTarBase 2020: Updates to the Experimentally Validated MicroRNA-Target Interaction Database. Nucleic Acids Res. 2020, 48, D148-D154. [CrossRef] [PubMed]

54. Sun, J.; Zhu, Y.; He, X.; Ding, Z.; Dong, H.; Feng, Y.; Yu, X.; Zhao, D.; Wu, H.; Feng, L.; et al. Activation of SIRT1 Deacetylase As a Therapeutic Approach for Myelodysplastic Syndromes By Restoring TET2 Function. Blood 2017, 130. [CrossRef]

55. Kanehisa, M. KEGG: Kyoto Encyclopedia of Genes and Genomes. Nucleic Acids Res. 2000, 28, 27-30. [CrossRef]

56. Song, S.J.; Ito, K.; Ala, U.; Kats, L.; Webster, K.; Sun, S.M.; Jongen-Lavrencic, M.; Manova-Todorova, K.; Teruya-Feldstein, J.; Avigan, D.E.; et al. The Oncogenic MicroRNA MiR-22 Targets the TET2 Tumor Suppressor to Promote Hematopoietic Stem Cell Self-Renewal and Transformation. Cell Stem Cell 2013, 13, 87-101. [CrossRef]

57. Zeng, Z.; Xia, L.; Fan, S.; Zheng, J.; Qin, J.; Fan, X.; Liu, Y.; Tao, J.; Liu, Y.; Li, K.; et al. Circular RNA CircMAP3K5 Acts as a MicroRNA-22-3p Sponge to Promote Resolution of Intimal Hyperplasia via TET2-Mediated SMC Differentiation. Circulation 2021, 143, 354-371. [CrossRef] [PubMed]

58. Fráguas, M.S.; Eggenschwiler, R.; Hoepfner, J.; dos Santos Schiavinato, J.L.; Haddad, R.; Oliveira, L.H.B.; Araújo, A.G.; Zago, M.A.; Panepucci, R.A.; Cantz, T. MicroRNA-29 Impairs the Early Phase of Reprogramming Process by Targeting Active DNA Demethylation Enzymes and Wnt Signaling. Stem Cell Res. 2017, 19, 21-30. [CrossRef] [PubMed]

59. Zhang, Z.; Cao, Y.; Zhai, Y.; Ma, X.; An, X.; Zhang, S.; Li, Z. MicroRNA-29b Regulates DNA Methylation by Targeting Dnmt3a/3b and Tet1/2/3 in Porcine Early Embryo Development. Dev. Growth Differ. 2018, 60, 197-204. [CrossRef]

60. Chen, Q.; Li, X.; Kong, L.; Xu, Q.; Wang, Z.; Lv, Q. MiR-101-3p Induces Vascular Endothelial Cell Dysfunction by Targeting Tet Methylcytosine Dioxygenase 2. Acta Biochim. Biophys. Sin. 2020, 52, 180-191. [CrossRef]

61. Liu, J.; Guo, B.; Chen, Z.; Wang, N.; Iacovino, M.; Cheng, J.; Roden, C.; Pan, W.; Khan, S.; Chen, S.; et al. MiR-125b Promotes MLL-AF9-Driven Murine Acute Myeloid Leukemia Involving a VEGFA-Mediated Non-Cell-Intrinsic Mechanism. Blood 2017, 129, 1491-1502. [CrossRef] [PubMed]

62. Jin, H.; Li, D.-W.; Wang, S.-N.; Luo, S.; Li, Q.; Huang, P.; Wang, J.-M.; Xu, M.; Xu, C.-X. MiR-125a Promotes the Progression of Giant Cell Tumors of Bone by Stimulating IL-17A and $\beta$-Catenin Expression. Mol. Ther. Nucleic Acids 2018, 13, 493-502. [CrossRef]

63. Zhaolin, Z.; Jiaojiao, C.; Peng, W.; Yami, L.; Tingting, Z.; Jun, T.; Shiyuan, W.; Jinyan, X.; Dangheng, W.; Zhisheng, J.; et al OxLDL Induces Vascular Endothelial Cell Pyroptosis through MiR-125a-5p/TET2 Pathway. J. Cell. Physiol. 2019, 234, 7475-7491. [CrossRef] 
64. Ren, S.; Xu, Y. AC016405.3, a Novel Long Noncoding RNA, Acts as a Tumor Suppressor through Modulation of TET2 by MicroRNA-19a-5p Sponging in Glioblastoma. Cancer Sci. 2019, 110, 1621-1632. [CrossRef]

65. Li, N.; Liu, L.; Liu, Y.; Luo, S.; Song, Y.; Fang, B. MiR-144-3p Suppresses Osteogenic Differentiation of BMSCs from Patients with Aplastic Anemia through Repression of TET2. Mol. Ther. Nucleic Acids 2020, 19, 619-626. [CrossRef] [PubMed]

66. Qi, X.-B.; Jia, B.; Wang, W.; Xu, G.-H.; Guo, J.-C.; Li, X.; Liu, J.-N. Role of MiR-199a-5p in Osteoblast Differentiation by Targeting TET2. Gene 2020, 726, 144193. [CrossRef]

67. Peng, B.; Li, C.; He, L.; Tian, M.; Li, X. MiR-660-5p Promotes Breast Cancer Progression through down-Regulating TET2 and Activating PI3K/AKT/MTOR Signaling. Braz. J. Med. Biol. Res. 2020, 53, e9740. [CrossRef]

68. Ko, M.; An, J.; Bandukwala, H.S.; Chavez, L.; Äijö, T.; Pastor, W.A.; Segal, M.F.; Li, H.; Koh, K.P.; Lähdesmäki, H.; et al. Modulation of TET2 Expression and 5-Methylcytosine Oxidation by the CXXC Domain Protein IDAX. Nature 2013, 497, 122-126. [CrossRef] [PubMed]

69. Guilhamon, P.; Eskandarpour, M.; Halai, D.; Wilson, G.A.; Feber, A.; Teschendorff, A.E.; Gomez, V.; Hergovich, A.; Tirabosco, R.; Fernanda Amary, M.; et al. Meta-Analysis of IDH-Mutant Cancers Identifies EBF1 as an Interaction Partner for TET2. Nat. Commun. 2013, 4, 2166. [CrossRef]

70. Boller, S.; Li, R.; Grosschedl, R. Defining B Cell Chromatin: Lessons from EBF1. Trends Genet. 2018, 34, 257-269. [CrossRef] [PubMed]

71. Fernandez-Jimenez, N.; Sklias, A.; Ecsedi, S.; Cahais, V.; Degli-Esposti, D.; Jay, A.; Ancey, P.B.; Woo, H.D.; Hernandez-Vargas, H.; Herceg, Z. Lowly Methylated Region Analysis Identifies EBF1 as a Potential Epigenetic Modifier in Breast Cancer. Epigenetics 2017, 12, 964-972. [CrossRef] [PubMed]

72. Costa, Y.; Ding, J.; Theunissen, T.W.; Faiola, F.; Hore, T.A.; Shliaha, P.V.; Fidalgo, M.; Saunders, A.; Lawrence, M.; Dietmann, S.; et al. NANOG-Dependent Function of TET1 and TET2 in Establishment of Pluripotency. Nature 2013, 495, 370-374. [CrossRef] [PubMed]

73. Jiao, J.; Jin, Y.; Zheng, M.; Zhang, H.; Yuan, M.; Lv, Z.; Odhiambo, W.; Yu, X.; Zhang, P.; Li, C.; et al. AID and TET2 Co-Operation Modulates FANCA Expression by Active Demethylation in Diffuse Large B Cell Lymphoma: AID and TET2 Cooperation Modulates FANCA. Clin. Exp. Immunol. 2019, 195, 190-201. [CrossRef] [PubMed]

74. Weissman, A.M.; Shabek, N.; Ciechanover, A. The Predator Becomes the Prey: Regulating the Ubiquitin System by Ubiquitylation and Degradation. Nat. Rev. Mol. Cell Biol. 2011, 12, 605-620. [CrossRef] [PubMed]

75. Nakagawa, T.; Lv, L.; Nakagawa, M.; Yu, Y.; Yu, C.; D’Alessio, A.C.; Nakayama, K.; Fan, H.-Y.; Chen, X.; Xiong, Y. CRL4VprBP E3 Ligase Promotes Monoubiquitylation and Chromatin Binding of TET Dioxygenases. Mol. Cell 2015, 57, 247-260. [CrossRef]

76. Chen, L.; Smith, M.D.; Lv, L.; Nakagawa, T.; Li, Z.; Sun, S.-C.; Brown, N.G.; Xiong, Y.; Xu, Y. USP15 Suppresses Tumor Immunity via Deubiquitylation and Inactivation of TET2. Sci. Adv. 2020, 6, eabc9730. [CrossRef]

77. Raffel, S.; Falcone, M.; Kneisel, N.; Hansson, J.; Wang, W.; Lutz, C.; Bullinger, L.; Poschet, G.; Nonnenmacher, Y.; Barnert, A.; et al. BCAT1 Restricts AKG Levels in AML Stem Cells Leading to IDHmut-like DNA Hypermethylation. Nature 2017, 551, 384-388. [CrossRef] 